\title{
Correction to: Spatiotemporal assessment of the PERSIANN family of satellite precipitation data over Fars Province, Iran
}

\section{Narjes Salmani-Dehaghi ${ }^{1} \cdot$ Nozar Samani ${ }^{1}$}

Published online: 12 July 2019

(C) Springer-Verlag GmbH Austria, part of Springer Nature 2019

\section{Correction to: Theoretical and applied climatology} https://doi.org/10.1007/s00704-019-02872-2

The original version of this article unfortunately contained a mistake.

Equations 1-4 have been typed wrongly during the steps of corrections and some figures and tables are placed way too far from the citations. The publisher regrets this mistake.

The original article has been corrected.

RMSE $=\sqrt{\frac{\sum_{\mathrm{i}=1}^{\mathrm{N}}\left(\mathrm{P}_{\mathrm{io}}-\mathrm{P}_{\mathrm{is}}\right)^{2}}{\mathrm{~N}}}$

$\mathrm{RME}=\frac{\overline{\mathrm{P}}_{\mathrm{o}}-\overline{\mathrm{P}}_{\mathrm{s}}}{\overline{\mathrm{P}}_{\mathrm{o}}}$

The online version of the original article can be found at https://doi.org/ 10.1007/s00704-019-02872-2

Nozar Samani

samanin@shirazu.ac.ir

1 Department of Earth Sciences, Shiraz University, Shiraz 7143673565, Iran

$$
\mathrm{CC}=\frac{\sum_{\mathrm{i}=1}^{\mathrm{N}}\left(\mathrm{P}_{\mathrm{io}}-\overline{\mathrm{P}}_{\mathrm{o}}\right)\left(\mathrm{P}_{\mathrm{is}}-\overline{\mathrm{P}}_{\mathrm{s}}\right)}{\sqrt{\sum_{\mathrm{i}=1}^{\mathrm{N}}\left(\mathrm{P}_{\mathrm{io}}-\overline{\mathrm{P}}_{\mathrm{o}}\right)^{2} \sum_{\mathrm{i}=1}^{\mathrm{N}}\left(\mathrm{P}_{\mathrm{is}}-\overline{\mathrm{P}}_{\mathrm{s}}\right)^{2}}}
$$

$$
\mathrm{R}^{2}=\left(\frac{\sum_{\mathrm{i}=1}^{\mathrm{N}}\left(\mathrm{P}_{\mathrm{io}}-\overline{\mathrm{P}}_{\mathrm{o}}\right)\left(\mathrm{P}_{\mathrm{is}}-\overline{\mathrm{P}}_{\mathrm{s}}\right)}{\sqrt{\sum_{\mathrm{i}=1}^{\mathrm{N}}\left(\mathrm{P}_{\mathrm{io}}-\overline{\mathrm{P}}_{\mathrm{o}}\right)^{2} \sum_{\mathrm{i}=1}^{\mathrm{N}}\left(\mathrm{P}_{\mathrm{is}}-\overline{\mathrm{P}}_{\mathrm{s}}\right)^{2}}}\right)^{2}
$$

where $\mathrm{P}_{\mathrm{O}}$ is observed ground-based precipitation, $\mathrm{P}_{\mathrm{S}}$ is satellite-based precipitation, $\bar{P}_{\mathrm{O}}$ the mean observed precipitation, $\bar{P}_{\mathrm{S}}$ the mean satellite precipitation, $\mathrm{i}$ is the summation index or the record number in the precipitation time series and $\mathrm{N}$ is number of months, seasons and years depending on the time series scale.

Publisher's note Springer Nature remains neutral with regard to jurisdictional claims in published maps and institutional affiliations. 